\title{
sciendo
}

\section{Effects of Concurrent Strength and High-Intensity Interval Training on Fitness and Match Performance in Water-Polo Players}

\author{
by \\ Petros G. Botonis ${ }^{1}$, Argyris G. Toubekis ${ }^{1,2}$, Gerasimos D. Terzis ${ }^{2}$, \\ Nickos D. Geladas ${ }^{3}$, Theodoros I. Platanou ${ }^{1}$
}

The purpose of the study was to examine changes in performance and match-induced fatigue over a 27-week training period. Eight national-level water-polo players performed a $5 \times 200 \mathrm{~m}$ swimming test to calculate velocities corresponding to blood lactate concentration of 4.0, 5.0 and 10.0 mmoll-1-1 at three testing periods: i) baseline, ii) end of the pre-season ( 8 weeks of $4 \times 4$ min swimming bouts), iii) end of the in-season ( 8 weeks of $8 \times 20$ m swimming sprints). During each testing period, four competitive matches were played and repeated sprints $(8 \times 20 \mathrm{~m}), 400 \mathrm{~m}$ swimming, and shooting accuracy were evaluated at the pre-and post-match. Repeated sprint tests were also conducted at mid-game. Analysis of variance for repeated measures was used to detect changes among training periods and within games. Swimming velocities corresponding to 4.0, 5.0 and 10.0 mmol. $t^{-1}$ were increased after the pre-season by $9 \%, 7.7 \%$, and $6.7 \%(p<0.01)$ and decreased following the in-season compared to the pre-season by $8.9 \%, 7.0 \%$ and $3.3 \%(p<0.01)$, respectively. Pre-match repeated sprints and $400 \mathrm{~m}$ performance were improved after the pre-season by $4.3 \%$ and $3.8 \%$ $(p<0.01)$ and decreased by $\sim 3 \%$ after the in-season compared to the pre-season $(p<0.01)$. Mid-and post-match repeated sprint performance was improved after the pre-season by $4.8 \pm 1.4 \%$ and $4.4 \pm 1.1 \%$ and remained unchanged after the in-season compared to the pre-season. Post-match $400 \mathrm{~m}$ speed was improved by $3.2 \%$ after the pre-season $(p<0.01)$ and decreased by $2.8 \%$ after the in-season $(p=0.04)$.Pre-season training improved players' aerobic endurance and performance. Intensified in-season training decreased aerobic power, endurance, and pre-match performance while maintaining match repeated sprint performance.

Key words: team-sports, physical fitness, match-induced fatigue.

\section{Introduction}

Successful playing a team sport requires the development of players' physical, technical and tactical skills with appropriately year-round planned training periodization including preseason and in-season periods (Mujika, 2009). In water-polo, daily sessions of pre-season training usually include a high-volume of continuous and/or interval training, together with strength and specific water-polo training. On the other hand, in-season training consists of lower-volume, high-intensity training maintaining physical fitness benefits obtained within the pre-season period and enhancing players' tactical efficiency.

High-intensity interval training (HIT) is defined as either repeated short ( $<45 \mathrm{~s}$ ) or long (2-4 min) bouts of rather high- but not maximal

\footnotetext{
1 - Division of Aquatic Sports, School of Physical Education and Sports Science, National and Kapodistrian University of Athens, Athens, Greece.

2 - Sports Performance Laboratory, School of Physical Education and Sports Science, National and Kapodistrian University of Athens, Athens, Greece.

3 - Division of Sport Medicine and Biology of Exercise, School of Physical Education and Sport Science, National and Kapodistrian University of Athens, Athens, Greece.
} 
intensity exercise or repeated sprint sequences interspersed with recovery periods (Buchheit and Laursen, 2013). HIT such as $4 \times 4 \mathrm{~min}$ and sufficient 3-min rest intervals between efforts $\left(\mathrm{HIT}_{4 \times 4}\right)$ has been widely used at in the pre-season period increasing exercise performance variables in already trained water-polo players (Botonis et al., 2016a). In particular, Botonis et al. (2016a) showed important increments in variables depicting aerobic and anaerobic potential such as swimming velocity corresponding to 4.0, 5.0 and $10.0 \mathrm{mmol}^{-1} \mathrm{l}^{-1}$ (V4, V5, V10) after $\mathrm{HIT}_{4 \times 4}$ concurrently performed with strength and specific water-polo training. Additionally, HIT with repeated sprints (HITRS) reproduces water-polo match demands (Melchiorri et al., 2010; Platanou, 2004; Tan et al., 2009) and is utilized to improve the repeated sprint ability of the players, which is considered a key-component to competitive success in team-sports (Spencer et al., 2005). However, the efficacy of the above-mentioned training methods when applied as part of real setting training with regard to physical fitness and sport-specific variables has never been examined in team sports and in water-polo particularly.

An increased conditioning level of the playersis linked with the match-induced fatigue which impairs critical physical and technical abilities such as repeated sprint performance, 400 $\mathrm{m}$ swimming time and shooting accuracy (Botonis et al., 2016b, 2016c).To date, it is unknown whether HIT applied within the pre-season and the subsequent in-season period has a positive effect on alleviating the match-induced fatigue.

The purpose of the study was to examine the changes in performance variables and the match-induced fatigue over a 27-week training period. It was hypothesized that: i) pre-season training including $\mathrm{HIT}_{4 \times 4}$ concurrently performed with strength and specific water-polo training would improve important exercise performance variables (V4, V5, V10), ii) in-season training including $\mathrm{HIT}_{\mathrm{RS}}$ concurrently performed with strength and specific water-polo training would further enhance exercise performance, and, iii) both $\mathrm{HIT}_{4 \times 4}$ and $\mathrm{HIT}_{\mathrm{RS}}$ would equally alleviate decrements of physical/technical abilities.

\section{Methods}

\section{Participants}

Eight male outfield players (age: $27 \pm 6$ years, body height: $183 \pm 7 \mathrm{~cm}$, body mass: $90 \pm 12$ $\mathrm{kg}$ ) of the top-level division of the Greek championship participated in the study and provided written informed consent before its commencement. The study was approved by the Faculty review board of the University of Athens and conformed to the Declaration of Helsinki. The compliance rate of $80 \%$ for all training periods was the criteria for completion of the study.

\section{Measures}

A $5 \times 200 \mathrm{~m}$ progressively increasing swimming speed test was performed by all players (Tsekouras et al., 2005). Fingertip blood samples were taken after each $200 \mathrm{~m}$ repetition and were immediately analyzed for the determination of lactate concentration (Accusport, Boehringer, Germany). Velocities corresponding to 4.0, 5.0 and 10.0 mmol: $^{-1}$ (V4, V5, and V10) were calculated from the swimming speed $v s$. lactate concentration curve by interpolation of the second order polynomial function. The lactate tolerance rating was defined as the differential velocity between blood lactate concentrations of 5.0 and $10.0 \mathrm{mmol} \cdot \mathrm{l}^{-}$ ${ }^{1}$ (V10-V5) (Pyne et al., 2001).

The repeated sprint swimming test that was applied in the present study involved $8 \times 20 \mathrm{~m}$ maximal freestyle swimming efforts with $10 \mathrm{~s}$ recovery in between (Botonis et al., 2016b; 2016c). The participants' percentage decrement score $\left(S_{\mathrm{dec}}\right)$ for repeated sprints was calculated as previously suggested (Girard et al., 2011). For the shooting accuracy assessment, players performed 5 shots as fast and as accurately as possible toward a wooden target $(0.40 \times 0.60 \mathrm{~m})$ attached to the goalpost, with a $0.30 \mathrm{~m}$ diameter hole in its center to allow the ball to pass through when shooting was accurate. Five points were granted when the ball passed through the target hole, three points if the ball failed to pass through the target hole, but partially covered it, one point if the ball made contact with the edge of the target hole and zero points if the ball did not make contact with the target. Immediately after the shooting accuracy test, the $400 \mathrm{~m}$ swim test was performed with the race being started in the water.

On a separate day, the one repetition maximum (1RM) test on the bench press was performed for the evaluation of maximal strength. Design and Procedures

The timing of training and testing during the experimental period is presented in Figure 1. 
Within a 27-week training period, starting with two-week familiarization, the players completed 8 weeks of pre-season training, including $\mathrm{HIT}_{4 \times 4}$ and 8 weeks of in-season training including HITRs. At three different stages within the 27-week plan, before and after the pre-season as well as after the in-season training period, a series of four highly competitive friendly matches were played. These took place within a two-week period (3 testing periods, including 4 matches each, 12 matches in total were analyzed). A five-week period separated the pre-season and the in-season period (2 weeks for the matches and 3 weeks of recovery training). Two days before the first of the four-match series at the beginning of pre-season training (baseline) and after the end of both pre-season and in-season periods, the players' fitness level was evaluated through the incremental swimming test $(5 \times 200$ $\mathrm{m})$. Additionally, repeated sprints and 400-m tests were performed after the recovery training period. At the start (Pre), the middle (Mid) and after (Post) each match a series of performance tests were applied. Repeated sprints, 400-m freestyle swimming and shooting accuracy tests were performed at the Pre- and Post-match. In the Midphase, players performed a repeated sprint test only. It was pre-arranged that the participants would play the entire match with no substitution.

\section{Training content}

The water-polo players followed two different modes of HIT which were applied in preseason (HIT ${ }_{4 \times 4}$ ) and in-season (HITRs) training. It is known that high-intensity training with long work intervals such as $\mathrm{HIT}_{4 \times 4}$ induces considerable improvements in significant physiological variables (V4, V5, V10) (Botonis et al., 2016a). Moreover, HITRS is also used empirically in water polo training as it reproduces match demands (Melchiorri et al., 2010; Platanou, 2004; Tan et al., 2009). The pre-season training period consisted of HIT $_{4 \times 4}$ combined with maximal strength and specific water-polo training. $\mathrm{HIT}_{4 \times 4}$ required players to perform $4 \times 4$ min bouts of freestyle swimming at an intensity that corresponded to $\sim 106 \%$ of $\mathrm{V} 4$, interspersed with $3 \mathrm{~min}$ of active recovery at self-selected intensity (twice a week). The total swimming distance covered in each session was approximately $1770 \mathrm{~m}$ (swimming bouts: $1170 \mathrm{~m}$, active recovery: $600 \mathrm{~m}$ ). In addition, all players participated in a dry-land, maximal strength training program twice a week (4 sets of 4 to 5 repetitions at 85 to $90 \% 1 \mathrm{RM})$. The exercises (bench press, seated pull-down, triceps press, shoulder press, and leg press) targeted specific muscles that are mainly used in water polo: pectoralis major, latissimus dorsi, triceps, deltoids, and quadriceps. Specific water-polo training consisted of a) sprint training (once a week), b) technical training (5-6 days a week), c) tactical training (5-6 days a week). All players participated in one friendly match per week (Table 1).

Following preseason training, a two week period was spent to complete the friendly matches and additional 3-week recovery training was completed. During this period, the training time given for physical conditioning was reduced and more training time was spent on tactics development. Within the recovery training period, maximal strength training was reduced to once a week and high-intensity training sessions were replaced by low-intensity training. All players participated in one official match per week (Table $1)$.

In-season training consisted of HITRS together with maximal strength and specific waterpolo training. HITRS involved $4-5$ sets of $8 \times 20 \mathrm{~m}$ maximal freestyle swimming efforts. Each effort was interspersed by $10 \mathrm{~s}$ of passive rest. Four min of active recovery at self-selected intensity was given between sets.Therepeated sprintsessions were performed twice a week. In addition, dryland strength training characteristics remained similar to pre-seasonal training, but its frequency was reduced (once a week). A greater amount of training time was devoted to team tactics development. All players participated in one official match per week (Table 1).

\section{Statistical analysis}

The normality of the data was verified by the Shapiro-Wilk test. One-way ANOVA for repeated measures was applied to detect changes across training periods in physical fitness-related variables. A three-way ANOVA with repeated measures was performed to identify differences between baseline, pre-season and in-season periods in match-induced changes (Pre, Mid, Post) in repeated sprints, the $400 \mathrm{~m}$ test, and shooting accuracy. A two-way ANOVA with repeated measures on two factors (training periods $\mathrm{x}$ match tests) was employed to identify changes in the 400 $\mathrm{m}$ test. A Tukey post-hoc test was used to locate significant differences between means. Post-hoc 
analysis of power was calculated using G-Power 3.1.9.2 for Windows software (Faul et al., 2007). As a measure of effect size, the Cohen's $d$ was calculated. Values of $0.20,0.50$ and above 0.80 were considered as small, medium and large, respectively. Considering the sample size in the present study $(\mathrm{n}=8)$, an effect size of 1.15 was required to achieve a power value greater than 0.8 . Data are expressed as mean \pm standard deviation (SD) and $90 \%$ of confidence limits (CL) were also calculated.Statistical significance was set at $p<0.05$.

\section{Results}

Fitness and performance changes during the 27-week period

The influence of different training modes on a typical swimming speed vs. lactate concentration curve is presented in Figure 2a. Derived variables of V4, V5 and V10 were enhanced pre-seasonally compared to baseline and decreased following in-season training (Figure 2b). No changes were observed in V10-V5 between baseline and pre-season training $(p=0.93)$, whereas improvement was shown after in-season compared to pre-season training $(39.0 \pm 28.0 \%, p=$ $0.006, d=1.4)$. Strength increased pre- seasonallycompared to baseline (baseline: $109 \pm$ 14.3 vs. pre-season: $118 \pm 15.6 \mathrm{~kg} ; p=0.01, d=2.5$ ) and remained unchanged after in-season compared to pre-seasontraining $(116 \pm 13.2 \mathrm{~kg} ; p=$ $0.40)$.

Pre-match mean repeated sprint performance was improved after pre-season training compared to baseline and was decreased after in-season training compared to pre-season returning to baseline levels (Table 2, Figure 2b). In this line, $S_{\text {dec }}$ was greater in baseline compared to subsequent training periods, but similar between pre-season and in-season training (baseline: $15.8 \pm$ $3.0 \%$, pre-season: $11.0 \pm 3.9 \%$, in-season: $10.6 \pm$ $2.5 \%, p=0.03$ and $p=0.01, d=2.63$ and 2.16, respectively). Additionally, $400 \mathrm{~m}$ performance was improved after pre-season compared to baseline and decreased after in-season training (Table 2, Figure 2b). No changes were observed for shooting accuracy at all time points (baseline vs. pre-season vs. in-season, $p=0.49$, Table 2). Moreover, both mean repeated sprint time and 400 $\mathrm{m}$ performance were similar between the preseasonand the recovery training period $(p=0.29$ and $p=0.62$, respectively).

\section{Table 1}

A detailed outline of the training modes applied during pre-season training, recovery training, and in-season training. HITRs: high-intensity interval training with

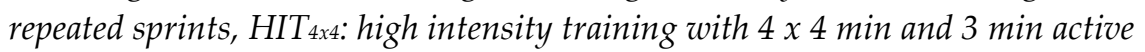
recovery, STR: strength training, tech+tact: technical and tactical training, LIT: lowintensity aerobic training.

\begin{tabular}{|c|c|c|c|c|c|c|c|}
\hline $\begin{array}{l}\text { Training } \\
\text { period- } \\
\text { duration }\end{array}$ & Monday & Tuesday & Wednesday & Thursday & Friday & Saturday & Sunday \\
\hline $\begin{array}{c}\text { Pre-season } \\
- \\
8 \text { weeks }\end{array}$ & $\begin{array}{c}\mathrm{HIT}_{4 \times 4}(30 \\
\text { min), } \\
\text { tech+tact } \\
(45 \mathrm{~min})\end{array}$ & $\begin{array}{c}\text { STR } \\
(50-60 \\
\text { min }) \\
\text { tech+tact } \\
(45 \text { min })\end{array}$ & $\begin{array}{c}\mathrm{HIT}_{4 \times 4}(30 \\
\text { min), } \\
\text { tech+tact } \\
(45 \mathrm{~min})\end{array}$ & $\begin{array}{c}\text { STR } \\
\text { (50-60 min), } \\
\text { tech+tact } \\
(45 \text { min })\end{array}$ & $\begin{array}{c}\text { sprint } \\
\text { training } \\
(30 \mathrm{~min}) \\
\text { tech+tact } \\
(45 \mathrm{~min})\end{array}$ & $\begin{array}{l}\text { Friendly } \\
\text { match }\end{array}$ & Rest \\
\hline $\begin{array}{l}\text { Recovery } \\
\text { training - } \\
3 \text { weeks }\end{array}$ & $\begin{array}{c}\text { LIT } \\
(20 \mathrm{~min}) \\
\text { tech+tact } \\
(30 \mathrm{~min})\end{array}$ & $\begin{array}{l}\text { tech+tact } \\
(45 \mathrm{~min})\end{array}$ & $\begin{array}{l}\text { STR (50 } \\
\text { min) } \\
\text { tech+tact } \\
(45 \text { min })\end{array}$ & $\begin{array}{c}\text { LIT } \\
(20 \mathrm{~min}) \\
\text { tech+tact } \\
(45 \mathrm{~min})\end{array}$ & $\begin{array}{c}\text { sprint } \\
\text { training } \\
(20 \mathrm{~min}) \\
\text { tech+tact } \\
(45 \mathrm{~min})\end{array}$ & $\begin{array}{l}\text { Match- } \\
\text { play/ rest }\end{array}$ & $\begin{array}{l}\text { Match- } \\
\text { play/ rest }\end{array}$ \\
\hline $\begin{array}{l}\text { In-season } \\
-8 \text { weeks }\end{array}$ & $\begin{array}{c}\text { LIT } \\
(20 \mathrm{~min}) \\
\text { tech+tact } \\
(30 \mathrm{~min})\end{array}$ & $\begin{array}{l}\text { HITRs: }(20 \\
\text { min), } \\
\text { tech+tact } \\
(60 \mathrm{~min})\end{array}$ & $\begin{array}{l}\text { STR (50 } \\
\text { min) } \\
\text { tech+tact } \\
(60 \mathrm{~min})\end{array}$ & $\begin{array}{l}\text { HITRS }(20 \\
\text { min) } \\
\text { tech+tact } \\
(45 \text { min })\end{array}$ & $\begin{array}{l}\text { sprint } \\
\text { training } \\
(20 \mathrm{~min}) \\
\text { tech+tact } \\
(45 \mathrm{~min})\end{array}$ & $\begin{array}{l}\text { Match- } \\
\text { play/ rest }\end{array}$ & $\begin{array}{l}\text { Match- } \\
\text { play/rest }\end{array}$ \\
\hline
\end{tabular}


Table 2

Performance variables (Mean \pm SD) before (Pre), at the middle (Mid) and after (Post) water polo matches performed at the end of the transition period (Baseline), at the end of pre-season and after in-season training. The relative performance changes, confidence limits $(\%, \pm C L 90 \%)$ for Pre-Mid, Mid-Post and Pre-Post match tests as well as effect sizes (d) for each comparison are also included. RS: repeated sprints, SA:

shooting accuracy, ${ }^{*}$ Significant difference from baseline, $p<0.01, \ddagger$ Significant difference from pre-season, $p<0.01$, \# Significant difference from Pre, $p<0.01$.

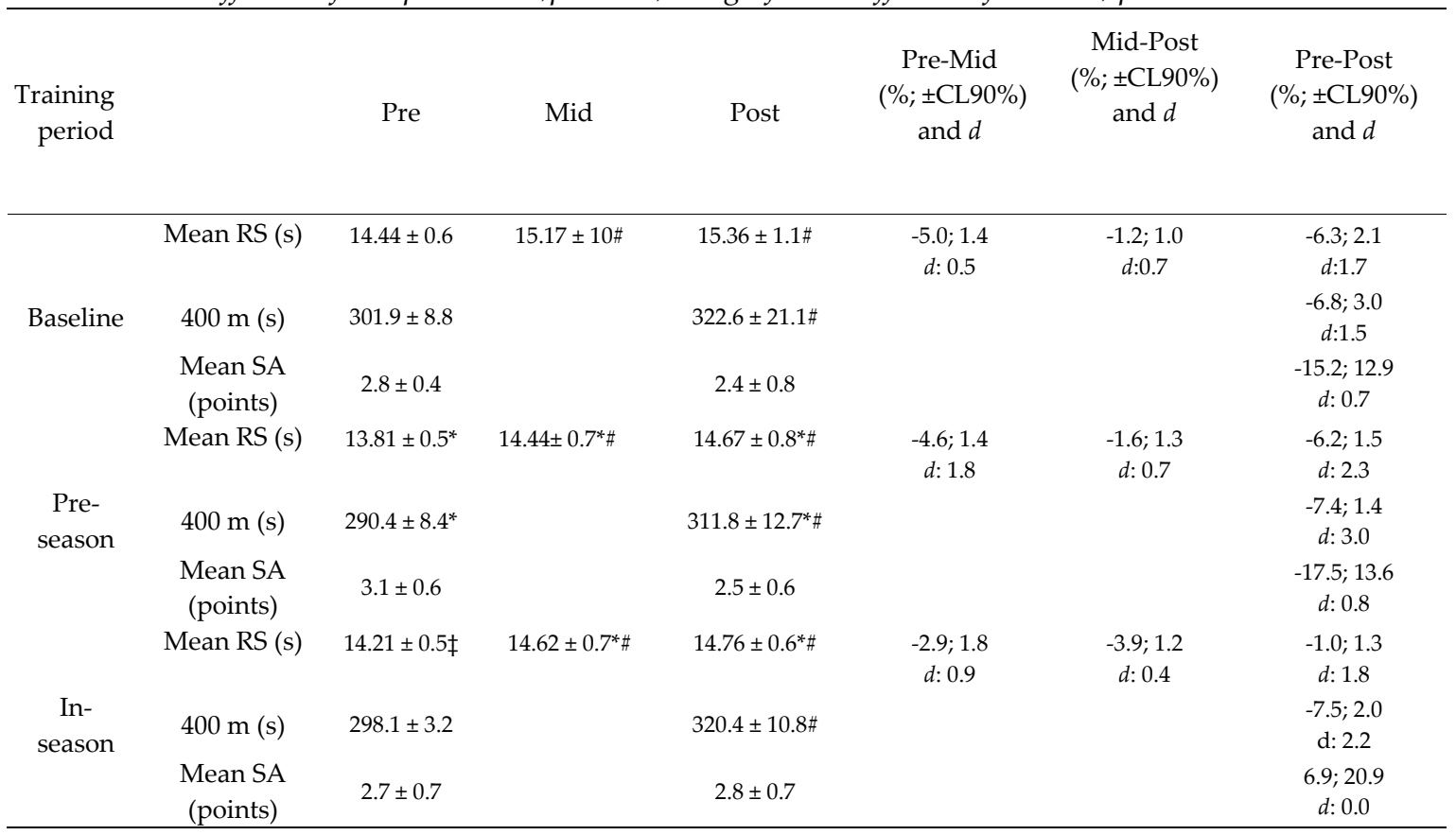
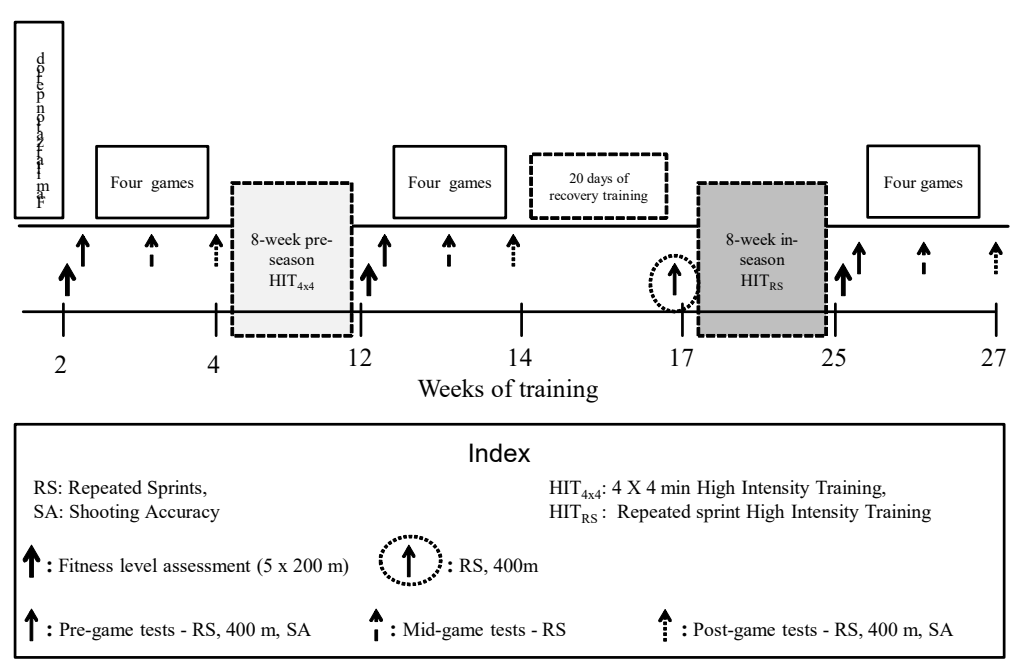

Figure 1

The study protocol overview. Each arrow represents the time point of testing for all tests (see Index). 


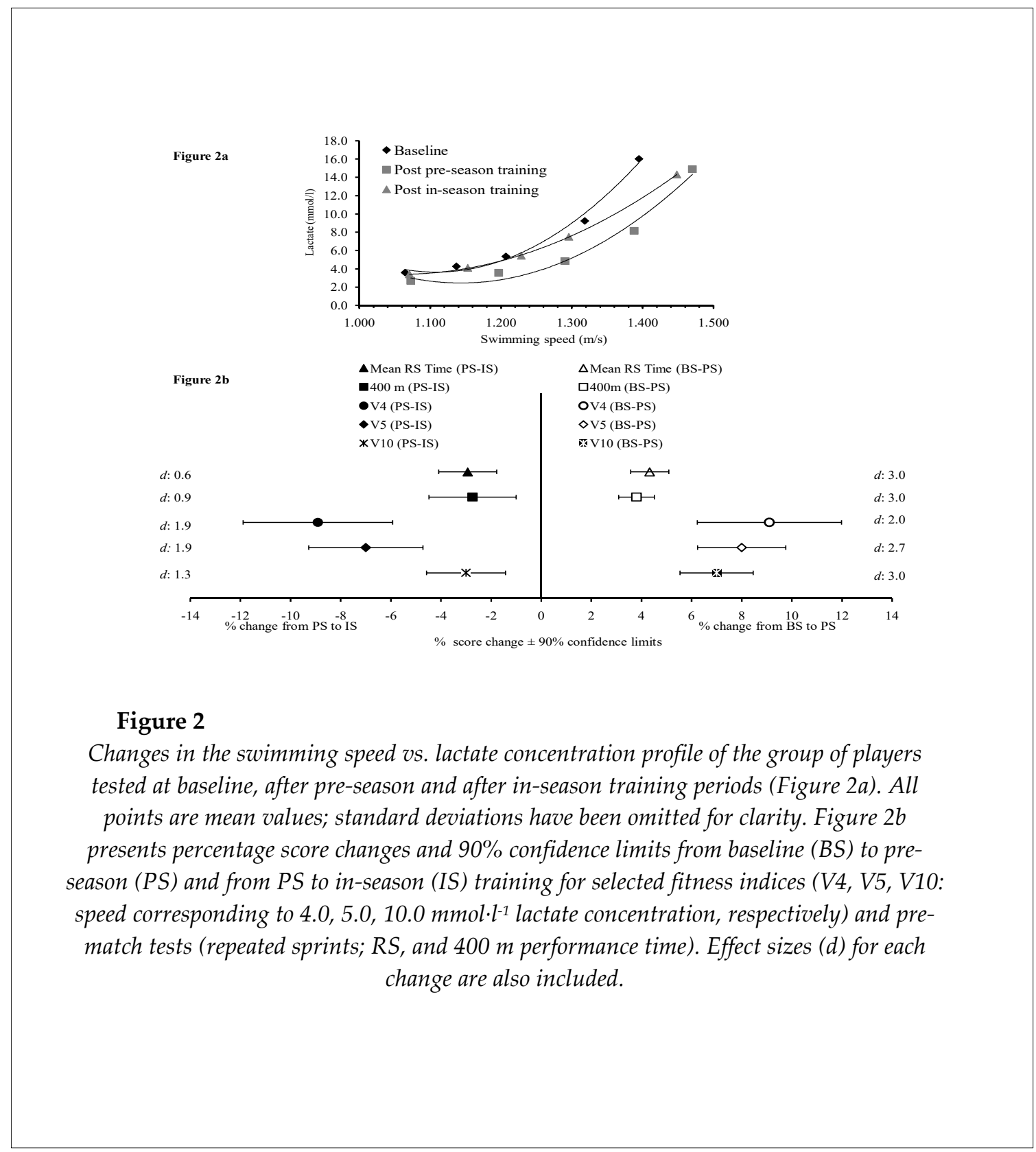

Within match performance changes during the 27-week period

Regardless of the training period, repeated sprints and 400-m performance were decreased as the match progressed (Table 2), while no changes were observed between Mid- and Post-match tests for mean repeated sprint time $(p=0.28)$. Mean shooting accuracy tended to decrease towards the end of the match $(p=0.08)$.

In both the Mid- and Post-match measurements, mean repeated sprint performance was greater after pre-season training compared to baseline (Mid: $4.7 \pm 2.3 \%$, Post: $4.4 \pm 1.9 \%, p<0.001$, $p<0.001, d=1.84$ and $d=2.0$, respectively, Table 2). Likewise, the mean repeated sprint performance was greater in the Mid- and Post-match test after in-season training compared to baseline $(p<0.001$, $p=0.001, d=0.9, d=1.0$, respectively, Table 2 ). No differences were shown between pre-season and in-season periods ( $p=0.40$ and $p=0.95)$. However, $S_{\text {dec }}$ was similar in Mid and Post between baseline (Mid: $11.6 \pm 4.0$, Post: $9.7 \pm 3.7 \%$ ), pre-season training (Mid: $9.2 \pm 3.5 \%$, Post: $12.3 \pm 4.9 \%$ ) and in- 
season training

(Mid: $10.2 \pm 3.2 \%$, Post: $10.4 \pm 7.0 \%, p>0.05$ ). Regarding the 400-m post match test, a better performance was observed after pre-seasonthan both baseline $(3.2 \pm 2.7 \%, p=0.001, d=1.1)$ and inseason training $(2.8 \pm 2.6 \%, p=0.001, d=1.1)$. Both training periods had no influence on shooting accuracy reduction from the start to the end of the match $(p>0.05)$.

\section{Discussion}

This study is the first to provide new insight into the effects of different HIT modes applied within a real-setting training season on physical fitness and sport-specific performance measures. The main findings are that: a) players following pre-season HIT4x4 combined with maximal strength and specific water-polo training, showed significant improvements in aerobic fitness and enhanced exercise performance, $b$ ) inseason HITRS induced improvements in anaerobic indices, but decreased aerobic power and capacity which returned to baseline levels, and c) both HIT4x4 and HITRS attenuated match-induced fatigue indices.

According to the first hypothesis, the enhanced performance in Pre-game tests after preseason training may be attributed to the improvements in participants' aerobic and anaerobic capacity. In fact, the improvement of V4 by $9 \%$ after HIT4x 4 is in accordance with previous findings in water-polo (Botonis et al., 2016a) and suggests that the fatigue index in repeated sprints may be reduced after endurance improvements (Bishop et al., 2011). Interval swimming at intensities and duration similar to those applied in the present study elicits the heart rate and VO2 responses approaching $>90 \%$ (Bentley et al., 2005) and this stimulus induces significant cardiovascular as well as peripheral adaptations (i.e. increased $\mathrm{O} 2$ transport and utilization, an increased lactate metabolism in type II muscle fibers; Buchheit and Laursen, 2013; Kohn et al., 2011). Apart from improvement of aerobic and metabolic variables, the speed corresponding to anaerobic training pace was also enhanced as a result of pre-season HIT4x4, that was indicated by the improvement of V10 by 7\%. It is likely that the high neuromuscular loads applied pre-seasonally may also lead to anaerobic performance enhancement (Buchheit and Laursen, 2013a).
In contrast to our second hypothesis, inseason HITRS combined with strength and specific water-polo training did not further enhance exercise capacity of our participants. On the contrary, performance was reduced in Pre-match tests after in-season compared to the corresponding values measured after pre-season training. There are no reports concerning the effects of HITRS on water-polo, however, a considerable decrease in V4 was shown after the in-season compared to the end of pre-season training in the present study. Conversely, large increments in the lactate tolerance (V10-V5, 39\%) were observed. This indicates increased anaerobic potential. It was expected that repeated sprints with incomplete recovery intervals would highly activate both the anaerobic and aerobic metabolism (Peyrebrune et al., 2014), leading to aerobic and anaerobic potential enhancement. However, this was not the case in the present study, where it seems that only anaerobic potential was enhanced. Although the present experimental setting does not allow direct comparisons between HIT modes, the negative changes in the selected fitness variables observed after HITRS (Figure 2a) indicate its detrimental effects on aerobic capacity when this type of training is applied in-seasonally. It should be noted that a 3-week period of recovery training was included between pre-season and inseason periods and this was applied after two weeks including highly competitive friendly matches. Thus, any changes observed after inseason training should be considered with the possible physiological alterations induced within two weeks of matches and the recovery training period. This period of reduced volume and intensity may have induced adaptations similar to a taper period within the first two weeks but deterioration later. Therefore, players benefited from the recovery training period, but presented deterioration in their fitness level as this period extended. Indeed, elongation of this period (i.e. $>2$ weeks as in the present study) may decrease selected fitness variables (Van Handel et al., 1988). Additionally, it is likely that after completing two training sessions of repeated $20 \mathrm{~m}$ bouts per week for the eight-week period, players received increased neuromuscular loads (carry-over effect). Thus, they may require a period of tapering to show significant improvements in endurance capacity. It is recognized that adequate 
recovery sessions are required to allow team-sport players to maintain high-intensity training during the in-season (Buchheit and Laursen, 2013a).

It was also assumed in our third hypothesis that both training programs (HIT4X4 and HITRS) would attenuate match-induced fatigue indices. In fact, it was expected that the aforementioned training modes would alleviate the decrements of performance towards the end of the game through different physiological pathways; specifically, HIT4x4 through improvements in aerobic capacity, whereas HITRS through the high activation of the aerobic and anaerobic metabolism and increased buffering capacity (Ronnestad et al., 2014), both leading to attenuation of match-induced fatigue. In accordance with our hypothesis, considerable improvements were observed in mean repeated sprints and $400 \mathrm{~m}$ time after pre-season HIT4x4 training at Mid- and Post-match measurements. Moreover, the repeated sprint ability was maintained in the Mid- and Post-match tests after the in-season period despite a lower pre-match performance.

It is well-documented that long interval training such as HIT4x 4 positively affects repeated sprint performance through enhanced aerobic contribution, increased lactate removal and phosphocreatine restoration (Tomlin and Wenger, 2001). Accordingly, it decreases reliance on carbohydrates and more lipids are used at the same relative exercise load leading to greater muscle glycogen sparing (Perry et al., 2008). As a consequence, the greater exercise capacity in repeated sprints and $400 \mathrm{~m}$ tests at all time points of the match may also be linked to improvements in swimming economy.

A new finding of the present study is the maintenance of repeated sprint ability in the Mid and Post-match tests after the in-season HITRS period despite a lower pre-match performance. As it has also been reported, anaerobic potential is a crucial constraint for the repeated sprint ability of water-polo players (Meckel et al., 2013). In fact, the increased lactate tolerance observed after in-season HITRS indicates increased anaerobic potential and may be linked with the maintenance of exercise performance in the Mid and Post-match tests. Besides, previous studies in water-polo demonstrated that intensified training improved exercise capacity (Botonis et al., 2016a;
D'Ercole et al., 2012). Despite the maintenance of repeated sprint ability within the match, $400 \mathrm{~m}$ performance at the Post-match test was deteriorated. The meaningful descent of players' aerobic capacity (V4) after in-season training is probably the main explanation. Since $400 \mathrm{~m}$ performance is related to the players' ability to resist the game-induced fatigue (Botonis et al., 2016c), it emerges that in-season HITRS should be applied with caution (i.e. lower frequency and/or volume). It seems that HITRS may be effective for repeated sprint maintenance, but detrimental to aerobic capacity. The lower exercise capacity observed in most of the tests after the in-season period may have been influenced by the accumulation of fatigue in the last part of in-season training. In this case, the quantification of the internal training load (Lupo et al., 2014a) throughout training sessions would be useful providing more information on the effects of different training modes on fitness and matchrelated performance variables.

In line with previous water-polo studies (Botonis et al., 2016a; Saez de Villarreal et al., 2014), the strength level of players was improved $(\sim 6 \%)$ in the bench press pre-seasonally. Additionally, both training periods had no impact on shooting accuracy at pre- and post-match tests. Although it has been reported that the fitness level may affect technical skills (Botonis et al., 2016c), the present data indicate that physical fitness enhancement alone was not enough to improve shooting accuracy at pre- and post-match tests.

The current experimental setting simulated a realistic training plan of a 27 -week period. Decreased performance after the in-season period may be attributed to the long duration or low intensity content of the previous recovery training which separated pre-season and in-season training, or to an inappropriate stimulus within inseason training per se.

We acknowledge that the current study presents some limitations. The experimental setting, with a limited number of players $(n=8)$ does not allow for direct comparisons between HIT4x4 and HITRS training programs since they were applied in this specific order in consecutive training periods. Moreover, we did not measure the internal training load of our participants. Most possibly, the measurement of the internal training load would have allowed us to draw a safer 
conclusion regarding the effects of different modes of HIT on players' physiological responses and performance.

Several practical implications can be derived from this study which may be helpful for coaches in the construction of training programs. First, our data indicate that HIT4x4 is effective at improving exercise performance and attenuating the water-polo match-induced fatigue. As a consequence, it should be used in training practice. Moreover, HITRS may also be used as it is efficient at maintaining the repeated sprint ability within a high-competitive match. Nonetheless, coaches should be aware that high volume (4-5 sets of $8 x$ $20 \mathrm{~m}$ ) and high frequency (twice per week) inseason repeated sprint training is not appropriate to maintain aerobic capacity and should be supplemented with aerobic stimuli to maintain athletes' physical fitness. Additionally, recovery periods of more than 3 weeks between seasons may deteriorate the players' physical abilities and the training plan should focus on their maintenance. Overall, highintensity interval training with $4 \times 4$ min may be preferable compared to repeated sprint training in enhancing water-polo specific fitness and performance variables within a long duration training period. Last, but not least, the strength gains obtained following pre-season concurrent training are maintained during the in-season period when a high-resistance training stimulus is applied once a week.

We conclude that pre-season HIT4x4 together with maximal strength and specific waterpolo training enhances both aerobic and anaerobic fitness variables improving performance and attenuating match-induced fatigue. However, inseason training comprised of HITRS, maximal strength and specific water-polo training decreased aerobic capacity and pre-match related performance while maintaining within match repeated sprint performance.

\section{Acknowledgements}

We would like to thank the players for the participation in this study and the coach: Nickos Karamanis for his cooperation. We also like to thank: Panagiotis Miliotis, Spiridoula Ntalapera, Athanasios Simsiris and Dimitris Stergiopoulos for their technical assistance.

\section{References}

Bentley D, Roels B, Hellard P, Fauquet C, Libicz S, Millet G. Physiological responses during submaximal interval swimming training: effects of interval duration. J Sci Med Sport, 2005; 8: 392-402

Bishop D, Girard O, Villanueva AM. Repeated-sprint ability - Part II. Recommendations for training. Sports Med, 2011; 41: 741-756

Botonis PG, Toubekis AG, Platanou TI. Concurrent strength and interval endurance training in elite water polo players. J Strength Cond Res, 2016a; 30:126-133

Botonis PG, Toubekis AG, Platanou TI. Physical performance during water-polo matches: The effect of the players' competitive level. J Hum Kinet, 2016b; 54: 135-142

Botonis PG, Toubekis AG, Terzis GD, Geladas ND, Platanou TI. Performance decrement and skill deterioration during a water polo game are linked with the conditioning level of the athletes. J Strength Cond Res, 2016c;30: 1033-1041

Buchheit M, Laursen PB. High-intensity interval training, solutions to theprogrammingpuzzle. Part I: Cardiopulmonary Emphasis.Sports Med, 2013; 43: 313-338

Buchheit M, Laursen PB. High-intensity interval training, solutions to theprogrammingpuzzle. Part II: anaerobic energy, neuromuscular load and practical applications.Sports Med, 2013a; 43: 927-954

D'Ercole C, Gobbi M, D'Ercole C, Iachini F, Gobbi F. High intensity training for faster water polo. J Sports Med Phys Fitness, 2012; 52: 229-236

Dupont G, Akapko K, Berthoin S. The effect of in-season, high-intensity interval training in soccer players. J Strength Cond Res, 2004; 18: 584-589

Faul F, Erdfelder E, Lang A-G, Buchner A. G*Power 3: A flexible statistical power analysis program for social, behavioral, and biomedical sciences. Behav Res Methods, 2007; 39: 175-191 
Girard O, Mendez-Villanueva A, Bishop D. Repeated-sprint ability - Part I: factors contributing to fatigue. Sports Med, 2011; 41: 673-694

Kohn TA, Essen-Gustavsson B, Myburgh K. Specific muscle adaptations in type II fubers after high-intensity interval training of well-trained runners. Scand J Med Sci Sports, 2011; 21: 765-772

Lupo C, Capranica L, Tessitore A. The validity of session-RPE method for quantifying training load in water polo. Int J Sports Physiol Perform,2014a; 9: 656-660

Lupo C, Condello G, Capranica L,Tessitore A. Women's water polo World Championships: technical and tactical aspects of winning and losing teams in close and unbalanced games. J Strength Cond Res, 2014b; 27: $210-222$

Lupo C, Condello G, Tessitore A. Notational analysis of elite men's water polo related to specific margins of victory. J Sports Sci Med, 2012; 11: 516-525

Lupo C, Tessitore A, Minganti C, Capranica L. Notational analysis of elite and sub-elite water polo matches. J Strength Cond Res, 2010; 24: 223-229

Lupo C, Tessitore A, Minganti C, King B, Cortis C, Capranica L. Notational analysis of American women's collegiate water polo matches. J Strength Cond Res, 2011; 25: 753-757

Meckel Y, Bishop D, Rabinovich M, Kaufman L, Nemet D, Eliakim A. Repeated sprint ability in elite water polo players and swimmers and its relationship to aerobic and anaerobic performance. J Sports Sci Med, 2013; 12: 738-743

Melchiorri G, Castagna C, Sorge R, Bonifazi M. Game activity and blood lactate in men's elite water-polo players.J Strength Cond Res, 2010;24: 2647-2651

Mujika I. Tapering and peaking for optimal performance. Champain, IL: Human Kinetics; 2009

Perry CG, Heigenhauser GJ, Bonen A, Spriet LL. High-intensity aerobic interval training increases fat and carbohydrate metabolic capacities in human skeletal muscle. Appl Physiol Nutr Metab, 2008; 33: 11121123

Peyrebrune MC, ToubekisAG,Lakomy HK, Nevill AM. Estimating the energy contribution during single and repeated sprint swimming. Scand J Med Sci Sports, 2014; 24: 369-376

Platanou T. Time motion analysis of the international level water polo players. J Hum Mov Studies, 2004; 46, 319-331

Pyne DB, Lee H, Swanwick KM. Monitoring the lactate threshold in world-ranked swimmers. Med Sci Sports Exerc, 2001; 33: 291-297

Ronnestad BR, Hansen J, Vegge G, Tonnessen E, Slettalokken G. Short intervals induce superior training adaptations compared with long intervals in cyclists - An effort-matched approach.Scand J Med Sci Sports, 2014;25: 143-151

Saez de Villarreal E, Suarez-Arrones L, Requena B, Haff GG, Ramos-Veliz R. Effects of dry-land vs. in-water specific strength training on professional male water polo players' performance. J Strength Cond Res, 2014; 28: 3179-3187

Tan F, Polglaze T, Dawson B. Activity profiles and physical demands of elite women's waterpolomatch play.J Sports Sci, 2009; 27: 1095-1104

Tomlin D, Wenger $\mathrm{H}$. The relationship between aerobic fitness and recovery from high intensity intermittent exercise. Sports Med, 2001; 31: 1-11

Tsekouras YE, Kavouras SA, Campagna A, Kotsis YP, Syntosi SS, Papazoglou K, Sidossis LS. (2005) The anthropometrical and physiological characteristics of elite water polo players. Eur J Appl Physiol, 2005; 95: 35-41

Van Handel PJ, Katz A, Troup JP. Oxygen consumption and blood lactic acid response to training and taper. In Swimming science V. Edited by B. Ungerechts, K. Wilke and K. Reischle. Champaign IL: Human Kinetics, 269-275; 1988

\section{Corresponding author:}

\section{Petros G. Botonis}

Department of Aquatic Sports, School of Physical Education and Sports Science, University of Athens, Athens, Greece. -41, Ethnikis Antistasis Ave, 17237, Dafni, Greece.

Phone: +302107276065; +306974709907, E-mail: pboton@phed.uoa.gr 